\title{
Postoperative Sepsis in a Patient with Undiagnosed Anthrax
} Şarbon Tanısı Göz Ardı Edilmiş OIguda Cerrahi Sonrası Sepsis Tablosu

\author{
(1) Sema TEKIN ŞAHIN11, (1) Ayşe Özlem METE2, (1) ilkay KARAOĞLAN2 \\ ${ }^{1}$ Alaaddin Keykubat University, Alanya Training and Research Hospital, Clinic of Infectious Diseases and Clinical Microbiology, Antalya, Turkey \\ ${ }^{2}$ Gaziantep University Faculty of Medicine, Department of Infectious Diseases and Clinical Microbiology, Gaziantep, Turkey
}

Keywords: Bacillus anthracis, deri şarbonu, deri şarbonuna bağlı sepsis, surgery, penicillin $g$

Anahtar Kelimeler: Bacillus anthracis, cutaneous anthrax, sepsis associated with cutaneous anthrax, cerrahi, penisilin $g$

\section{Dear Editor,}

Anthrax is a zoonotic disease caused by Bacillus anthracis, a Gram-positive spore-forming aerobe or facultative anaerobe bacterium ${ }^{[1]}$. Bacillus anthracis may involve four main sites: pulmonary, cutaneous, gastrointestinal, and meningeal. Cutaneous anthrax is the most common form $(95 \%)^{[2]}$. Transmission usually occurs via exposure to infected animals or contaminated animal products. Spores are usually the infectious form that generally causes anthrax ${ }^{[1]}$.

Cutaneous anthrax is characterized by papules and vesicles in the early stages and followed by black eschar skin lesions. The incubation period is between 1-12 days. The lesions are usually painless but are accompanied by fever, weakness, headache, and regional lymphadenopathy. The mortality rate in cutaneous anthrax is less than $1 \%$ with antibiotherapy ${ }^{[3]}$. In cases of severe cutaneous anthrax, edema may involve the entire limb or the entire trunk from neck to groin. This is called malignant edema and is associated with inflammation of the skin. Occupational risk groups include butchers, livestock breeders, and veterinarians ${ }^{[1]}$.

Although the incidence of anthrax is decreasing globally, it is still common in Turkey, especially in the Central Anatolia and Eastern Anatolia regions. In the Gaziantep province, anthrax is not common; no human cases were reported there in 2009$2010^{[4]}$.

Here we present a patient with undiagnosed anthrax who developed sepsis following a surgical incision. This case is presented to highlight the need to avoid surgical interventions in patients with risk factors and clinical suspicion of anthrax.

A 31-year-old male patient presented to the emergency department with complaints of edema of the neck and face. He lived in Gaziantep and worked as an animal skinner. He stated that the swelling in his neck had started three days earlier after scratching a pimple on the left side of his neck, and had spread to his face and chest over the next day. The patient was admitted to the Department of Ear Nose Throat with a preliminary diagnosis of deep neck infection. On physical examination, fluctuation was noted during palpation of the left side of the neck and an incision was made; however, there was no drainage. Computed tomography of the neck revealed marked edema of the deep fascial fatty planes on the left side at the level of the laryngeal cartilage. After the consultation on postoperative day 1 , the patient was transferred to the Department of Infectious Diseases and Clinical Microbiology for follow-up and therapy.

Physical examination revealed diffuse edema of the face, neck, and the anterior chest wall. No bullous or crusted lesions were observed at the incision site. The patient did not have fever or any other findings. Laboratory tests showed his white blood cell (WBC) count was 30,300/ $\mathrm{mm}^{3}$ and C-reactive protein (CRP) level was $78 \mathrm{mg} / \mathrm{dl}$ (normal range: $0-5 \mathrm{mg} / \mathrm{dl}$ ). With a prediagnosis of cutaneous anthrax, Gram staining was done on a fresh slide prepared from a specimen obtained from the region of the neck incision. Multiple long, sporeless Gram-positive bacilli were detected. Blood culture samples were taken and incubated in 
an automated blood culture system (BD BACTEC ${ }^{\text {TM }}$ FX, USA). The incision site was also cultured.

Treatment was initiated with crystallized penicillin G (24 million iu/day, intravenously) for suspected cutaneous anthrax. The patient exhibited diffuse edema, respiratory distress, and hypotension and was given dexamethasone $60 \mathrm{mg} /$ day for two days. Culture of the incision site yielded gray, nonhemolytic colonies after 24 hours of incubation on sheep blood agar. The strains isolated from the incision site sample were identified as B. anthracis in the automated system (BD BACTEC ${ }^{\mathrm{TM}} \mathrm{FX}$, USA).

Results of follow-up blood analyses on day 3 indicated WBC count: $65,000 / \mathrm{mm}^{3}$, platelet count (PIt): $110,000 / \mathrm{mm}^{3}$, CRP: $121 \mathrm{mg} / \mathrm{dl}$, AST: $236 \mathrm{u} / \mathrm{L}$ (normal range: 5-34 u/l), ALT: $108 \mathrm{u} / \mathrm{L}$ (normal range: $0-55 \mathrm{u} / \mathrm{L}$ ).

Furthermore, the patient developed massive scrotal edema. Thoracic tomography was performed due to tachycardia (130/ $\mathrm{min})$ and tachypnea $(28 / \mathrm{min})$. Massive pleural effusion and pericardial effusion were observed. The patient had a score of 5 in the Sequential Organ Failure Assessment (SOFA) and a score of 2 on the qSOFA (Quick SOFA) ${ }^{[5]}$. On day 4 of antibiotherapy, the patient was evaluated as being in a septic state due to worsening clinical condition and thoracic tomography findings of infiltration in areas adjacent to pleural effusion. With the patient's consent, his therapy was changed to meropenem, vancomycin, and ciprofloxacin. Blood culture was negative. A crusted lesion developed at the neck incision site. Laboratory findings on day 10 of inpatient treatment were as follows: WBC:

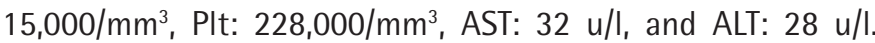
Regression in the pleural and pericardial effusion were observed on tomographic examination. The patient's antibiotherapy was continued for a total of 14 days. However, he was lost to followup after discharge, due to lack of cooperation (Figure 1).

Although anthrax is still an endemic infectious disease in Turkey, particularly in the Central Anatolia and Eastern Anatolia regions, its incidence is decreasing. According to data from the Turkish Ministry of Health, there were 396 cases in 2000, 148 in 2009, and 93 in 2010 ${ }^{[4]}$. Transmission of the most common form, cutaneous anthrax, is usually a result of exposure to infected animals or contaminated animal products. In direct contact with infected animal products, the bacillus enters through areas of compromised skin integrity; therefore, it is most commonly seen in exposed body parts such as the hands, arms, neck, and face $e^{[6-}$ ${ }^{8]}$. In our case, transmission probably occured while scratching the neck after contact with animal products.

Cutaneous anthrax is usually a self-limiting infection, and treatment lasts approximately 3-7 days in uncomplicated cases. Sepsis is very rare in patients with cutaneous anthrax. In a

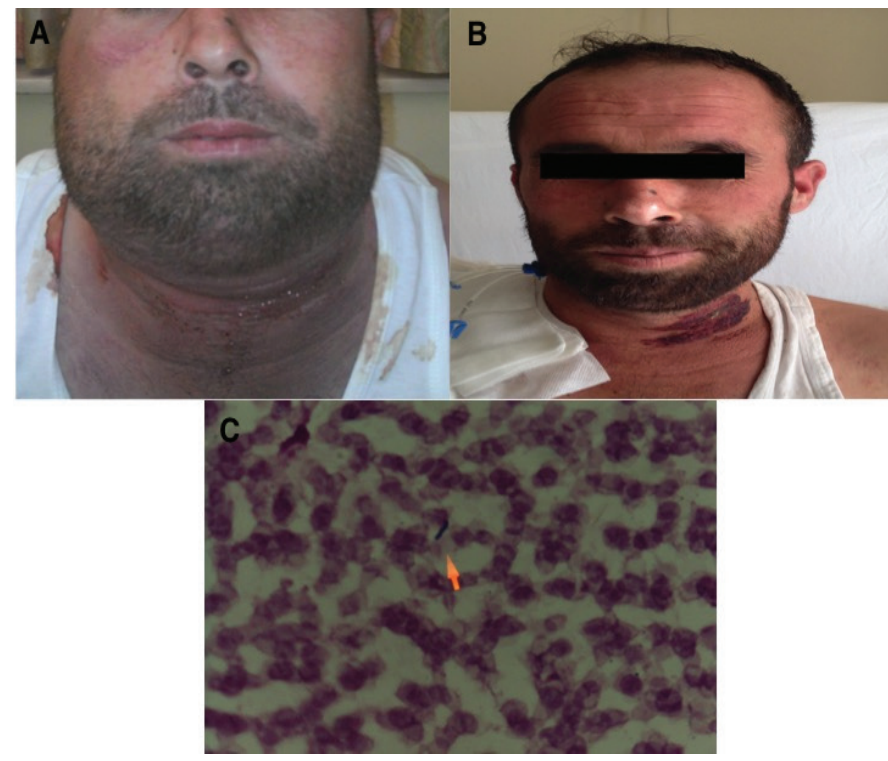

Figure 1. A) Malignant edema of the patient's neck, face, and anterior chest wall at presentation; B) Appearance of the lesion after treatment; C) Bacillus anthracis detected in Gram staining of a fresh slide prepared using a sample obtained from the neck incision site

study by Karahocagil et al. ${ }^{[9]}$, two of 85 patients with cutaneous anthrax developed sepsis. In another study by Baykam et al. ${ }^{[7]}$ evaluating 58 cases of cutaneous anthrax, only one patient developed clinical and laboratory-confirmed sepsis. Our patient exhibited tachycardia, tachypnea, fever, and B. anthracis growth in incision site culture and was diagnosed with sepsis associated with cutaneous anthrax.

Cutaneous anthrax is characterized by papules and vesicles in the early stages and by a black eschar in late stages ${ }^{[3]}$. As the lesion began as a pimple in our patient and was immediately followed by a surgical procedure, papules and vesicles were not observed, and the black eschar formed after treatment.

In cutaneous anthrax, surgical interventions are not recommended in patients with acute inflammation. Surgical interventions may lead to exacerbation of symptoms and enlargement of the lesion ${ }^{[10]}$. In this case, the patient did not exhibit tachycardia or tachypnea before incision, and developed clinical sepsis after the surgical intervention. This case also demonstrates the importance of consulting with Infectious Diseases and Clinical Microbiology Department for the benefit of the patient and the course of the disease.

Although the incidence of anthrax is decreasing globally, it is still a common infection in Turkey, especially in the Central Anatolia and Eastern Anatolia regions. As this case demonstrates, anthrax should be kept in mind in patients who work in occupational risk groups and have clinical signs suggesting anthrax. Surgical procedures should be avoided in suspected cases. 


\section{Ethics}

Informed Consent: Consent form was filled out by a participant.

Peer-review: Externally and internally peer-reviewed.

\section{Authorship Contributions}

Surgical and Medical Practices: S.T.Ş., A.Ö.M., I.K., Concept: S.T.Ş., A.Ö.M., I.K., Design: S.T.Ş., A.Ö.M., I.K., Data Collection or Processing: S.T.Ş., A.Ö.M., I.K., Analysis or Interpretation: S.T.Ş., A.Ö.M., I.K., Literature Search: S.T.Ş., A.Ö.M., I.K., Writing: S.T.Ş., A.Ö.M., I.K.

Conflict of Interest: No conflict of interest was declared by the authors.

Financial Disclosure: The authors declared that this study received no financial support.

\section{References}

1. Martin GJ, Friedlander AM. Bacillus anthracis (Anthrax) In: Mandell GL, Bennett JE, Dolin R, Blaser M (eds). Principles and Practice of Infectious Diseases. $8^{\text {th }}$ ed. Philadelphia: Elsevier Saunders, 2015:2391-409.
2. Lucey DR: Anthrax. In: Goldman L, Schafer Al (eds). Goldman's Cecil Medicine. 24 $4^{\text {th }}$ ed. Elsevier, Philadelphia: 2011:1837-40.

3. Brook I. The prophylaxis and treatment of anthrax. Int J Antimicrob Agents. 2002;20:320-5.

4. Ertek M. Current Situation of Anthrax in Turkey. ANKEM Derg. 2011;25(Suppl 2):88-91.

5. Marik EP, Taeb MA. SIRS, qSOFA and new sepsis definition, J Thorac Dis. 2017;9:943-5.

6. Doganay M, Metan G, Alp E. A review of cutaneous anthrax and its outcome. J Infect Public Health. 2010;3:98-105.

7. Baykam N, Ergonul O, Ulu A, Eren S, Celikbas A, Eroglu M, Dokuzoguz B. Characteristics of cutaneous anthrax in Turkey. J Infect Dev Ctries. 2009;3:599-603.

8. Demirdag K, Ozden M, Saral Y, Kalkan A, Kilic SS, Özdarendeli A. Cutaneous anthrax in adults: a review of 25 cases in the eastern Anatolian region of Turkey. Infection. 2003;31:327-30.

9. Karahocagil MK, Akdeniz N, Akdeniz H, Çalka Ö, Karsen H, Bilici A, Bilgili SG, Evirgen Ö, Cutaneous anthrax in Eastern Turkey: a review of 85 cases. Clin Exp Dermatol. 2008;33:406-11.

10. Öğütlü A. Anthrax. Journal of Experimental and Clinical Medicine. 2012;29:155-62. 